\title{
High-cycling-stability of Nanosized Sandwich Structure Silicon/Graphene Composite as Anode for Lithium-Ion Batteries
}

\author{
Rui Yang ", Yiding Shen, Xiaowu Yang, Liewei Qiu, Xin Li \\ Key Laboratory of Auxiliary Chemistry \& Technology for Chemical Industry, College of Chemistry \\ and Chemical Engineering, Shaanxi University of Science \& Technology, Xi'an 710021, P.R.China \\ *E-mail: yranthony@163.com
}

doi: $10.20964 / 2017.08 .81$

Received: 15 May 2017 / Accepted: 22 June 2017 / Published: 12 July 2017

The nanosized sandwich structure silicon/graphene composite anode material was designed to enhance anode performance for lithium-ion batteries (LIBs) by a facile method of mechanical ball milling. The structure and morphology of the materials were investigated by X-ray diffraction (XRD) and field emission scanning electron microscope (FESEM). The electrochemical properties of this composites electrode were studied by a series of electrochemical tests. As anode of LIBs, the composite material exhibited a high initial reversible capacity of $2189.7 \mathrm{mAh} \cdot \mathrm{g}^{-1}$ at a current density of $1000 \mathrm{~mA} \cdot \mathrm{g}^{-1}$, and showed an enhanced cyclic performance with a reversible capacity of $1212.9 \mathrm{mAh} \cdot \mathrm{g}^{-1}$ after 100 cycles. The performance improvement be attributed that as a good matrix, the graphene sheets mitigated the volume expansion/shrinkage of silicon during the lithiation/delithiation processes and increased electrical conductivity of anode materials.

Keywords: nano-Si powder, graphene nanosheets, lithium-ion batteries, composite anode material, electrochemical performance

\section{FULL TEXT}

(C) 2017 The Authors. Published by ESG (www.electrochemsci.org). This article is an open access article distributed under the terms and conditions of the Creative Commons Attribution license (http://creativecommons.org/licenses/by/4.0/). 